\title{
International Journal of Neuroscience
}

\section{Prooxidant-antioxidant balance, advanced oxidation protein products and lipid peroxidation in Serbian patients with Parkinson's disease}

Jadranka Miletić, Dunja Drakulić, Snežana Pejić, Marijana Petković, Tihomir V. Ilić, Milica Miljković, Aleksandra Stefanović, Milica Prostran \& Marina Stojanov

To cite this article: Jadranka Miletić, Dunja Drakulić, Snežana Pejić, Marijana Petković, Tihomir V. Ilić, Milica Miljković, Aleksandra Stefanović, Milica Prostran \& Marina Stojanov (2017):

Prooxidant-antioxidant balance, advanced oxidation protein products and lipid peroxidation in Serbian patients with Parkinson's disease, International Journal of Neuroscience, DOI: 10.1080/00207454.2017.1403916

To link to this article: http://dx.doi.org/10.1080/00207454.2017.1403916

Accepted author version posted online: 17

Nov 2017.

Submit your article to this journal $₫$

Q View related articles $\asymp$

View Crossmark data $₫$ 


\author{
PUBLISHER: TAYLOR \& FRANCIS \\ JOURNAL: INTERNATIONAL JOURNAL OF NEUROSCIENCE
}

DOI: HTTPS://DOI.ORG/10.1080/00207454.2017.1403916

\title{
PROOXIDANT-ANTIOXIDANT BALANCE, ADVANCED OXIDATION PROTEIN PRODUCTS ANL LIPID PEROXIDATION IN SERBIAN PATIENTS WITH PARKINSON'S DISEASE
}

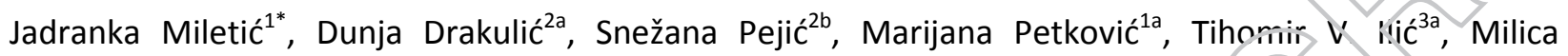
Miljković $^{4 a}$, Aleksandra Stefanović $^{4 b}$, Milica Prostran $^{5 a}$, Marina Stojanov $^{4 c}$

1 University of Belgrade - VINČA Institute of Nuclear Sciences, Departmerit of Physical chemistry, Mike Petrovića Alasa 12-14, P.O. Box 522, 11001 Belgrude, Republic of Serbia, amarijanapetkovic@vin.bq.ac.rs

2 University of Belgrade - VINČA Institute of Nuclear Sciences, Deprartment of Molecular Biology and Endocrinology, Mike Petrovića Alasa 12-14, P.O. Box 522, 11001 Belgrade, Republic of Serbia, adrakulic@vin.bg.ac.rs, ${ }^{b}$ snezana@vin.bg.ac.rs

3 University of Defense - Medical Faculty of Niedicu! Nilitary Academy, Clinic of Neurology, Crnotravska 17, 11000 Belgrade, Republic of Serbia, ¿ihoilic@ymail.com

4 University of Belgrade - Facu!ty of Pharmacy, Department of Medical Biochemistry, Vojvode Stepe 450, 11221 Belgrade, Repubi:ic of Seroia, milicammiljkovic@gmail.com, balex@pharmacy.bg.ac.rs, cstmarina@pharmacy.jug ac rs

5 University of Be!grade-School of Medicine, Department of Pharmacology, Clinical Pharmacology and

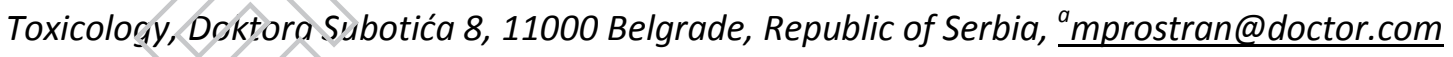

Runririg title: Oxidative stress in patients with Parkinson's disease.

Corresponding author:

Jadranka Miletić

Department of Physical chemistry 
VINČA Institute of Nuclear Sciences

University of Belgrade

P.O.Box 522

11001 Belgrade

Republic of Serbia

Phone: +381 113408293

Fax: +381 118066434

e-mail: jadranka@vin.bg.ac.rs

Keywords: Parkinson's disease, prooxidant-antioxidant balance, advanced oxidation protein products, malondialdehyde, 4-hydroxynonenal

\section{Abstract}

Background. Biomarkers of oxidative stress are relevant in the evaluation of the disease status and prooxidant-antioxidant balance, advariced oxidation protein products and lipid peroxidation products (malondialdehyde and 4-hydroxyncnenal) are being extensively evaluated regarding their relationship with clinical presentation and disease severity.

The aim of study was to evaivate the levels of above mentioned parameters in plasma of 39 men and 17 women with Parkirison's disease, originated from the Republic of Serbia and their relation to clinicopatholegical characteristics (gender, age at examination, duration of the disease, and Hoehn and Yahr score) and oxidative status.

Results The incidence of disease was 2:1 towards males. The investigated oxidative parameters were gender and Hoehn and Yahr related. Significant association of higher Hoehn and Yahr scores was observed for malondialdehyde $(p=0.01)$ and prooxidant/antioxidant balance $(p=0.02)$. Relation b£-tween oxidant/antioxidant status was further supported by observed positive correlation between 4hydroxynonenal $(p=0.04)$ and prooxidant-antioxidant balance $(p=0.03)$. Finally, the multivariate analysis indicated that prooxidant/antioxidant balance and malondialdehyde were partially determined 
by gender (10.6\% and 7.6\%) and Hoehn and Yahr scores (13.6\% and 18.8\%), while Hoehn and Yahr scores contributed to the variance of advanced oxidation protein products with $13.2 \%$.

Conclusion. Our results indicate the higher level of oxidative stress (oxidant/antioxidant imbalance) and possible relation of several markers with gender and disease stage in patients with Parkinson's disease The analyzed markers could be used to specify the severity of oxidative stress; however their pctentia! value should be analyzed in further studies. 


\section{Introduction}

Parkinson's disease (PD) is the second most common neurodegenerative disorder affecting approximately 1 percent of the worldwide population older than 55 years. According to recent metaanalysis, an overall prevalence of PD is 315 per 100000 individuals, which intensifies gradually with age, increasing from 428 per 100000 in the age group 60-69 years, to 1903 per 100000 individuals in the group aged 80 years and older [1]. Statistically, it is more frequent in males (65.5 per 100000 personyears) than females (36.5 per 100000 person-years) [2]. The average mortality rate of pacierits wirh PD is 2 per 100000 individuals, while in Republic of Serbia it is 3.43 per 100000 citizens, seing one of the highest in Europe [3].

This gradual but progressive chronic condition is manifested by carainal motor features such as rigidity, bradykinesia, postural instability, and tremor as well as by non-motor symptoms that include constipation, autonomic dysfunction, neuropsychiatric problems, and senisory and sleep difficulties [4]. In general, these symptoms usually develop as a resuit of degeneration and selective loss of dopaminergic neurons in substantia nigra pars compacta (SN roc $_{0}$ ), dopamine deficiency in corpus striatum and formation of intraneuronal inclusions of protein $\alpha$-synuclein (named Lewy bodies) [5] in mid-brain, brain stem and olfactory bulb.

Although PD was first described two centuries ago, the exact etiopathophysiological mechanisms of disease are still a matter of controversy. Arnong various putative factors that may contribute to PD pathogenesis, the neuroinflammation and oxidative damage may be the pivotal players. They could trigger the cascade of events leading to lipid, protein and DNA damage, cellular dysfunction and eventual cell death. Indeed, at cellular level, PD onset and progression might be associated with excessive generation of reactive oxygen/nitrogen species (ROS/RNS), modifications in catecholamine metabolism and a atioxidant (AO) protective systems, augmentation of iron deposition in SNpc [6] and with higney expression/increased levels of inflammatory mediators (cytokines and chemokines) [5].

Predlicts of lipid peroxidation, such as malondialdehyde (MDA) and 4-hydroxynonenal (4-HNE) might be suitable biomarkers for several diseases $[7,8]$ since they can propagate and amplify oxidative injury. MIDA is a reactive aldehyde generated by degradation of arachidonic acid and larger polyunsaturated fatty acids (PUFAs), while 4-HNE is produced as a major $\omega-6$ polyunsaturated fatty acids peroxidative decomposition and possesses cytotoxic, hepatotoxic, mutagenic, and genotoxic properties [9]. MDA appears to be the most mutagenic product of lipid peroxidation, whereas 4-HNE is the most toxic [10]. 
Beside lipids, proteins are one of the main targets of ROS. Advanced oxidation protein products (AOPPs) [11] are used as a degree of oxidative stress's protein damage in several pathological conditions like uremia and chronic renal failure $[12,13]$ as well as different neurological pathologies, such as multiple sclerosis [14], ALS [15], mitochondrial myopathies [16], etc. Additional candidate for PD biomarker is prooxidant-antioxidant balance (PAB), a state of dynamic balance generated under conditions of homoeostasis between free radicals that are produced and those utilized (scavenged) [17].

Since PAB, level of AOPP and lipid peroxidation end products (MDA and 4-HNE) might be tracers of oxidative stress and important in the pathogenesis of several neurodegenerative uilisorders, current study aims to estimate their levels in plasma of patients with PD and their correlation with clinicopathological features (gender, age at examination, duration of the disease, and Hoehn and Yahr staging).

\section{Materials and methods}

\section{Patients}

The study comprised 39 men and 17 women witi icliopathic PD, originated from the Republic of Serbia, aged 35-82 years. Patients were diagriosed according to the UK Parkinson's Disease Society Brain Bank Research criteria, UK, London [18] and staged according to H\&Y score [19] by neurologist experienced in movement disorders. All patients were on L-dopa medications. None of the patients in this study was diagnosed with the iH\&i score 5. Subjects with cancer history, marked autonomic disturbances, chronic renzi, inilar.matsry, liver, and hematological diseases and those on antipsychotic drugs were excluded froin the study.

Blood sampies were collected at the Clinic of Neurology, Medical Faculty of Medical Military Academy, University of Defense in Belgrade, Republic of Serbia, Belgrade, while all analysis were approved by tine local Ethics Committee according to the Declaration of Helsinki (1975). All participants provided written informed consent.

Biochemical measurements 
Peripheral blood samples were collected into Vacutainer (BD Diagnostics, Plymouth, UK) plastic tubes with $\mathrm{K}_{2}$ EDTA anticoagulant and centrifuged at $1500 \mathrm{~g}$, for $10 \mathrm{~min}$, at $4^{\circ} \mathrm{C}$, within $30 \mathrm{~min}$ of collection. Plasma was carefully separated and stored at $-80^{\circ} \mathrm{C}$ until further processing.

4-hydroxynonenal

The concentration of 4-HNE was determined by enzyme-linked immunosorbent assay for quantitative determination in human samples (Human HNE ELISA Kit, MyBioSource, Cálifornia, USA). Aliquots of standards and plasma samples $(50 \mu \mathrm{l})$ were added to a microtiter plate arid processed according to the manufacturer instructions. Concentration of $4-\mathrm{HNE}$ waS cetermined spectrophotometrically (LKB Vertriebs GmbH, DV 990 BV4-6, Austria) at 450 nin. bv conparing optical density (OD) of a sample to the standard curve. The standards and plasma samples were measured in one assay while differences between parallels were less than $6 \%$. The 4-HNE ievels are given as $\mu \mathrm{g} / \mathrm{ml}$.

Malondialdehyde

Plasma MDA concentration was monitored using TBARS assay according to [20]. Aliquots of blank (0.05 M TRIS HCl, pH 7.4), MDA standards (range of 1-10 $\mu \mathrm{mol} / \mathrm{l}$ ) and plasma samples (300 $\mu \mathrm{l}$ ) were added into $600 \mu \mathrm{l}$ of TBA-containing reagent iubes. TBA containing reagent is made from TCA (trichloroacetic acid), TBA and $\mathrm{HCl}$. After vortexing, heating for $5 \mathrm{~min}$ in a boiling water bath and cooling, they were centrifuged at $1000 \mathrm{~g}$, for $15 \mathrm{~mm}$, at $4^{\circ} \mathrm{C}$. The absorbance was measured on microplate reader at $535 \mathrm{~nm}$ and MDA levels are expressed as $\mathrm{pmol} / \mathrm{l}$.

\section{Advanced oxidation proteir prodicts}

AOPP levels were estimated according to Witko-Sarsat method [12]. Briefly, $400 \mu$ l of plasma sample was diluted in. P3S (1:5) while for the standard curve, $20 \mu \mathrm{l}$ of potassium iodide was added to $400 \mu \mathrm{l}$ of chloramine T solutior. The reaction was stopped with $40 \mu \mathrm{l}$ of acetic acid and the absorbance of the reaction mixture vvas measured in a microplate reader at $340 \mathrm{~nm}$. AOPP concentrations are expressed as jumol'? of chiloramine-T equivalents.

Prooxidant/antioxidant balance

Evaluation of PAB was performed according to the method by Almandari and coworkers [21]. Following the incubation for $2 \mathrm{~min}$ at room temperature in dark, $200 \mu \mathrm{l}$ of working solution (1 ml TMB cation solution with $10 \mathrm{ml} \mathrm{TMB}$ solution) was added to a 96 -well microtiter plate and, in each well, 
mixed with either $10 \mu$ of each plasma sample, standard or blank $\left(\mathrm{dH}_{2} \mathrm{O}\right)$, incubated in a dark place for $12 \mathrm{~min}$, at $37^{\circ} \mathrm{C}$ and, then the reaction was stopped by adding $100 \mu \mathrm{l}$ of $2 \mathrm{~N} \mathrm{HCl}$. According to the percentage of hydrogen peroxide in the standard solution, the values of PAB in plasma samples were determined with microplate reader at $450 \mathrm{~nm}$, with a reference wavelength of 620 or $570 \mathrm{~nm}$, ky comparing OD of a sample to the standard curve. PAB values are expresses in arbitrary units (HK).

\section{Statistical analysis}

The statistical analyses were performed using the GraphPad Prism and IBM SPSS 23.0 softvare. Data are expressed as mean \pm SD. The normality of the distribution was tested by Shapiro-Wills test. Since examined variables had non-Gausian distribution and based on the obtained mediail and percentile values, the variables cohort was divided into tertiles (subgroups with low, middle and high concentration) as previously reported [22]. Kruskal-Wallis test was used to test the differences among tertiles. To analyze the association of examined variables with demograpinic and clinical characteristics, the chi-square test was used. The Spearman univariate correiation was used the test the relation between AO/oxidant parameters, as well as between H:\&Y ssors/AO or oxidant variables. The general linear model (GLM) was used to test the univariate arid multivariate analysis. The $p$ value $<0.05$ was considered statistically significant.

\section{Results}

In current study, the average age of patients was $64.70 \pm 8.29$ years, and the majority was men (69.64 \%), while H\&Y scores 2 and 3 were almost equally represented (35.71\%, $32.14 \%$, respectively) (Table 1).

The associations of 4-HNE, MDA, PAB, and AOPP values with clinicopathological characteristics are summarized in Tab!e 2. For all investigated parameters, a significant difference among tertile subgroups was de:tected (4 ANE, $\mathrm{H}=48.22 ; \mathrm{MDA}, \mathrm{H}=44.59$; $\mathrm{AOPP}, \mathrm{H}=47.39 ; \mathrm{PAB}, \mathrm{H}=46.94 ; \mathrm{p}<0.001$, KruskalWal'is'.

There was a significant gender- difference in proportions of 4-HNE $(\chi 2 p=0.02), \operatorname{MDA}(\chi 2 p=0.04)$, arid PAB ( $\chi 2 \mathrm{p}=0.02)$ tertiles, while the association of the examined variables with H\&Y score was only observed for MDA ( $\chi 2 \mathrm{p}=0.01)$ and PAB $(\chi 2 \mathrm{p}=0.02)$ tertiles (Table 2$)$. 
Middle range values of MDA concentration were more frequent in H\&Y score 2 (51.61 \%), while high values $(>0.89 \mu \mathrm{g} / \mathrm{ml}$ ) were found in $71.43 \%$ of patients with H\&Y score 3 . On the other hand, the middle range $\mathrm{PAB}$ concentrations were observed in $37.04 \%$ of subjects with $\mathrm{H} \& \mathrm{Y}$ score 2 , whereas $57.14 \%$ of patients exhibited low PAB levels $(<9.46 \mathrm{HKU})$ in $\mathrm{H} \& \mathrm{Y}$ score 3 (Table 2). Although a significarit association was not found between PAB, oxidative parameters (4-HNE, MDA and AOPP) and age/disease duration factors, elevated concentrations of the examined parameters were more frequent in patierits aged 59 - 70 years than in any other age group, and among those with disease duration from $3-9.5$ years (Table 2).

Univariate correlation analysis between oxidant and $A O$ parameters indicated that $P / A B$ status was positively correlated with 4-HNE concentration (Figure $1(\mathrm{a})$ ), whereas there was no significant correlation between PAB and other oxidative parameters, such as MDA and AOPP (Figure 1 (b), (c) respectively).

The examination of relation between clinicopathological parameters and oxidant/AO status revealed a significant positive correlation $(p=0.02$ ) between age and MID. level (Figure $2(c)$ ) as well as between H\&Y score and AOPP concentration $(p=0.03$, Figure $3(d))$ There was no significant correlation between disease duration and PAB $(r=-0.04, p=0.98,4$. HIVE ir $=0.13, p=0.33), \operatorname{MDA}(p=-0.17, p=0.20)$, and AOPP $(r=0.04, p=0.76)$ levels.

Finally, the GLM univariate ana!ysis of individual associations between clinical and biochemical parameters is summarized in Tabie 3 , with eta values as a measure of the tightness of the association and explained variability. M? ultivariate analysis showed that gender is a significant variance component of PAB ( $F=5.587, p=0.022$, eta $10.6 \%)$ and almost shows the statistical significance of association with MDA scores $(F-3.840, p=0.056$, eta $7.6 \%)$. H\&Y score significantly effects MDA ( $F=3.628, p=0.020$, eta $18.8 \%$ ), while significant portions of the variance of PAB and AOPP (eta $13.6 \%, 13.2 \%$, respectively) were near the bordierline significance $(F=2.460, p=0.074 ; F=2.382, p=0.08$, respectively). Other associations were nct significant.

\section{Discussion}

The results of this study revealed that patients could be divided into cohorts according to different levels of investigated parameters. In general, these parameters were gender-, age- and H\&Y score- 
related. Literature highlights that PD is gender- and age-related disorder, as males and elder individuals are more predisposed $[23,24]$. Since later PD development in women could be associated with fertile life span, it is assumed that female sex hormones have beneficial effect and might postpone PD onset and progression [25]. In fact, the data presented herein are in accordance with those findings given that the incidence of PD was 2:1 towards males along with later onset of 4.43 years in female patients tran in males, contributing to differences between investigated groups.

Small amounts of ROS/RNS, are necessary for normal functioning of the cell since thev act as important second messengers. However, their overproduction and long term exposure is linked to malfunction of $\mathrm{AO}$ defense mechanisms and imbalance between oxidant/AO processes, inducing a progressive damage of DNA, proteins and lipids. PUFAs in membrane lipids are one of the main targets of ROS/RNS, whose peroxidation enable the generation of lipid hydroperoxides, like MDA and 4-HNE. Although MDA is more chemically stable and less toxic than 4-4NE, its bisiogical function and possible dual role are poorly understood. Just a few recent publications indicated that MDA may act as signaling messenger and regulator of gene expression and, thus, 'se poteritia!ly therapeutically valuable. However, most studies are focused on its detrimental effects since ic is believed that MDA is excessively formed under stress conditions and has high capability to react with various biomolecules, resulting in their biochemical alterations and massive accumulation, as sbserved in different pathological states [10]. For instance, increase of MDA content in cerebrospinal fluid was found in drug naive patients with PD [26]. In regard to the 4-HNE concentration, it is estimated at 0.05-0.15 mM in human blood and serum, whereas in pathological coriditions it is elevated (more than $100 \mathrm{mM}$ ) [27]. The high 4-HNE toxicity might be explained by the posi-translational modifications [7] of its downstream effectors such as proteins involved in the proieasome system, leading to system's failure and neuronal cell death [28]. Besides MDA and 4-ANJE, modulation of PAB level, a surrogate marker of factors that promotes and controls systemic oxidative stress, should be considered serious as the prolonged production of toxic species is related to oxidative stress-induced cell/tissue injuries, ultimately resulting in clinical diseases.

In current study, a gender-related association of MDA, 4-HNE and PAB plasma levels were implied, stress,ing the presence of potential biochemical basis for the epidemiologic differences in the disease susceptibility between male and female patients with PD. Further, a significant association of higher H\&Y scores and elevated MDA level was obtained. This finding might indicate the higher level of oxidative stress (oxidant/antoxidant imbalance) and suggest that MDA could be used to indicate the severity of oxidative stress in patients with PD. Finally, the relation between oxidant/antioxidant status 
in patients with PD is further supported by the observed correlation between 4-HNE levels and PAB levels.

No significant correlation between the disease's stage and lipid peroxidation parameters was detected most likely due to the fact that subjects involved in this study were in the different stages of disease. This finding is consistent with the study of Agil and coworkers [29], who reported the lack of the. same correlation given that clinical symptoms appear when PD is in advanced stage and approximately $80 \%$ of dopaminergic neurons in SNpc are already dead.

The correlation between the clinicopathological characteristics of patients and oxidafive parameters was shown to be positive between age and MDA level. The possible contithution of aging in the pathogenesis of PD is suggested by disease occurrence in late middle age and increased prevalence at older ages [30]. The observed accumulated level of lipid peroxides in elder patients with PD might be a result of prolonged exposure to overabundant free radicals derived from some endogenous or exogenous neurotoxic species that initiate coordinated recuction of PUFA content, as a substrate available for lipid peroxidation, and augmentation of MLA ievelis.

Besides lipids, other molecular targets of R.QS are proteins, the most abundant biomolecules in the organism, whose oxidation generates AOPP [11j. Although estimation of their levels is employed in monitoring of oxidative-stress-induced daniage to proteins in several neurodegenerative disorders, like mitochondrial myopathies or minitip!e sclerosis and amyotrophic lateral sclerosis [14], there is a scarce data about their enrollment in $\mathrm{PD}$ chset and its progression [31]. Just recently, Medeiros and coworkers [31] showed that AOPP/evel was significantly increased in patients with PD and proposed that it could be used as a potenilal marker ior evaluating the protein damage, which is linked to oxidative stress in PD. In this study a pusicive correlation between AOPP plasma level and H\&Y score was established. The increased ACPS leve! indicates a more profound oxidative damage to proteins and intensive inflamimatory cascade, which in turn causes a higher level of nervous tissue damage. This might result in a more severe: clinical picture of inflammation under conditions of disrupted defense potentials of the orgariism [32] in advanced stages of PD.

Finally, some issues need to be addressed, since present study has some limitations. There is a possibility that selection bias influenced the significance of our findings. Further research using the larger sample size and homogenous (gender, age, years since diagnosis) cohort is needed to confirm our 
results. Nevertheless, it provides the indications for the correlation between peripheral parameters of oxidative stress and clinicopathological features in PD patients.

\section{Conclusions}

In conclusion, our results show that several markers of oxidative stress in blood plasma are possibly related to gender and PD stage. We observed a correlation of gender with HNE, MDA and PAS that was further supported by GLM analysis regarding MDA and PAB level. In addition, H\&Y score deielmined a significant portion of MDA variance and possibly the PAB and AOPP level. Whether the examined parameters in this study could be used as indicators of oxidative stress in patien (s with $P L$ ) and severity of disease requires further research.

\section{Conflict of Interests}

The authors declare that there is no conflict of interests regarding the publication of this paper.

\section{Authors' Contribution}

JM performed experiments, acquisited data, suggested the methodology for their analyses and drafted the manuscript. DD participated in the-interpretation of obtained results and writing the manuscript whereas SP contributed to arialysis of data and drafting of the manuscript. AS and MM assisted during biochemical measurements. MP, TVI and MS designed and supervised experimental setup as well as edited the manuscript, $\mathrm{N}$ V also selected the patients for the study. All authors approved the final version of the mar:uscript.

\section{Acknowledgrients}

This study was supported by Ministry of Education, Science and Technological Development, Republic of Serbia (projects No 175023 and No 41014).

\section{Reierences}

[1] Pringsheim T, Jette N, Frolkis A, Steeves TDL. The prevalence of Parkinson's disease: a systematic review and meta analysis. Movement Disord. 2014; 29:1583-1590 
[2] Pringsheim T, Fiest $\mathrm{K}$, Jette $\mathrm{N}$. The international incidence and prevalence of neurologic conditions: how common are they? Neurology, 2014; 83:1661-1664

[3] worldlifeexpentancy.com. Data Source: Published By WHO 2014. Available from: http://www.worldlifeexpectancy.com/cause-of-death/parkinson-disease/by-country/

[4] Pickrell AM, Pinto M, Moraes CT. Mouse models of Parkinson's disease associated with mitochiondrial dysfunction. Mol Cell Neurosci. 2013; 55:87-94

[5] Rocha NP, Miranda AS, Teixeira AL. Insights into Neuroinflammation in Parkinsuri's Disease: From Biomarkers to Anti-Inflammatory Based Therapies. BioMed Res Int. 2015, http://dx.doi.org/10.1155/2015/628192

[6] Blesa J, Trigo-Damas I, Quiroga-Varela A, Jackson-Lewis VR. Oxidative stre.ss and Parkinson's disease. Front Neuroanat. 2015, http://dx.doi.org/10.3389/fnana.2015.00091

[7] Pizzimenti S, Ciamporcero E, Daga M, Pettazzoni P, Arsaro A, Cetrangolo G, Minelli R, Dianzani C, Lepore A, Gentile F, Barrera G. Interaction of aldekiydes derived from lipid peroxidation and membrane proteins. Front Physiol. 2013; 4:242

[8] EckI MP, Bresgen N. Genotoxicity of lipid oxiáation compounds. Free Rad Bio Med. 2017; 111: 244252

[9] Esterbauer H, Eckl P, Ortrier 4. Possibie mutagens derived from lipids and lipid precursors. Mutat Res Genet Toxicol. 1990; 238:223-233

[10] Ayala A, Mur̃oz FM, Argüelles S. Lipid Peroxidation: Production, Metabolism, and Signaling Mechanisms of Malenclialdehyde and 4-Hydroxy-2-Nonenal. Oxid Med Cell Longev 2014; 2014:360438

[11] Kancda H, Taguchi J, Ogasawara K, Aizawa T, Ohno M. Increased level of advanced oxidation protein producis in patients with coronary artery disease. Atherosclerosis 2002; 162:221-225

[12] Vitko-Sarsat V, Friedlander M, Capeillère-Blandin C, Nguyen-Khoa T, Nguyen AT, Zingraff J, Jungers P. Descamps-Latscha B. Advanced oxidation protein products as a novel marker of oxidative stress in uremia. Kidney Int. 1996; 49:1304-1313

[13] Witko-Sarsat V, Friedlander M, Nguyen Khoa T, Capeillère-Blandin C, Nguyen AT, Canteloup S, Dayer JM, Jungers $P$, Drüeke T, Descamps-Latscha B. Advanced oxidation protein products as novel mediators 
of inflammation and monocyte activation in chronic renal failure. J. Immunol Baltim Md 1950. 1998; $161: 2524-2532$

[14] Pasquali L, Pecori C, Lucchesi C, LoGerfo A, ludice A, Siciliano G, Bonuccelli U. Plasmatic oxidative stress biomarkers in multiple sclerosis: Relation with clinical and demographic characteristics. Ciin Biochem. 2015; 48:19-23

[15] Siciliano G, Piazza S, Carlesi C, Del Corona A, Franzini M, Pompella A, Malvaldi S, iviancuso M, Paolicchi A, Murri L. Antioxidant capacity and protein oxidation in cerebrospinal fluid of amyoirophic lateral sclerosis. J Neurol. 2007; 254:575-580

[16] Mancuso M, Orsucci D, Logerfo A, Rocchi A, Petrozzi L, Nesti C, Galetia F, Santoro G, Murri L, Siciliano G. Oxidative stress biomarkers in mitochondrial myopathies, basa!ly and after cysteine donor supplementation. J Neurol. 2010; 257:774-781

[17] Sahebkar A, Mohammadi A, Atabati A, Rahiman S, Tava!laie S, Iranshahi M, Akhlaghi S, Ferns GA, Ghayour-Mobarhan M. Curcuminoids Modulate Pro-Oxidant-Antioxidant Balance but not the Immune Response to Heat Shock Protein 27 and Oxidized LDL in Obese Individuals. Phytother Res. 2013; 27:1883-1888

[18] Hughes AJ, Daniel SE, Kiliord !., !ees AJ. Accuracy of clinical diagnosis of idiopathic Parkinson's disease: a clinicopathological siud, of 1 o cases. J Neurol Neurosur Ps. 1992; 55:181-184

[19] Hoehn MM, Yahr NiD. Parkinsonism onset, progression, and mortality. Neurology, 1967; 17:427-427

[20] Girotti MJ, Khan N McLellan BA. Early measurement of systemic lipid peroxidation products in the plasma of major blant trauma patients. J Trauma. 1991; 31:32-35

[21] Alamdari DH, Ghayour-Mobarhan M, Tavallaie S, Parizadeh MR, Moohebati M, Ghafoori F, KazemiBajescani SMR, Paletas K, Pegiou T, Koliakos G. Prooxidant-antioxidant balance as a new risk factor in patien.ts with angiographically defined coronary artery disease. Clin Biochem., 2008; 41:375-380

[22] Alcalay RN, Levy OA, Waters CH, Fahn S, Ford B, Kuo SH, Mazzoni P, Pauciulo MW, Nichols WC, GanOr Z, Rouleau GA, Chung WK, Wolf P, Oliva P, Keutzer J, Marder K, Zhang X. Glucocerebrosidase Activity in Parkinson's Disease with and without GBA Mutations. Brain2015; 138: 2648-2658 
[23] Smith KM, Dahodwala N. Sex differences in Parkinson's disease and other movement disorders. Exp Neurol. 2014; 259:44-56

[24] van den Eeden SK, Tanner CM, Bernstein AL. Fross RD, Leimpeter A, Bloch DA, Nelson LM. Incidence of Parkinson's disease: variation by age, gender, and race/ethnicity. The American Journal of Epidemiology, 2003; 157:1015-1022

[25] Bourque M, Dluzen DE, Di Paolo T. Neuroprotective actions of sex steroids in Parkinson's disease. Front Neuroendocrinol. 2009; 30:142-157

[26] Ilic TV, Jovanovic M, Jovicic A, Tomovic M. Func Neurolo. 1999; 14: 141-117

[27] Dalleau S, Baradat M, Guéraud F, Huc L. Cell death and diseases related to oxidative stress: 4hydroxynonenal (HNE) in the balance. Cell Death Differ. 2013; 20:1615-1630

[28] Jenner P. Oxidative stress in Parkinson's disease. Ann Neurol. 2003; 53 Suppl 3:S26-38

[29] Agil A, Durán R, Barrero F, Morales B, Araúizo Ni. A!ba F, Miranda MT, Prieto I, Ramírez M, Vives F. Plasma lipid peroxidation in sporadic Parkinson's áisease. Role of the I-dopa. J Neurol Sci. 2006; 240:3136

[30] Zigmond MJ, Burke RE. 20D2. Pathuphysiology of Parkinson's disease. In: Davis KL, Charney DD, Coyle JT, Nemeroff C, editors. Neuro pharmacology: the fifth generation of progress. Baltimore: Williams \& Wilkins; p 1781-94

[31] Medeiros MS, Senımacher-Schuh A, Cardoso AM , Vargas Bochi G, Baldissarelli J, Kegler A, Santana D, Chaves CNMBBS, Schetinger MRC, Moresco RN, Rieder CRM, Fighera MR. Iron and Oxidative Stress in Parkirison's Disease: An Observational Study of Injury Biomarkers. PLoS ONE, 2016; 11(1): e0146129. doi:10.1371 journal.pone.0146129

[32] E,isaga GN, Odinak MM, Boiko AN, Melnik YB, Popova NF. Treatment of Exacerbations of Multiple Sclerosis without the Use of Corticosteroids: The Role of Metabolic and Antioxidant Therapy. Neurosci Behav Physiol. 2012; 42:123-127 


\section{Legends to Figures}

Figure 1. Correlation between PAB and (a) 4-HNE, (b) MDA and (c) AOPP levels in plasma of patients with PD.

Figure 2. Correlation between age and (a) PAB, (b) 4-HNE, (c) MDA and (d) AOPP levels in piasina of patients with PD.

Figure 3. Correlation between H\&Y score and (a) PAB, (b) HNE, (c) MDA and (d) AOPP (elvels in plasma of patients with PD.

\section{Figure 1:}
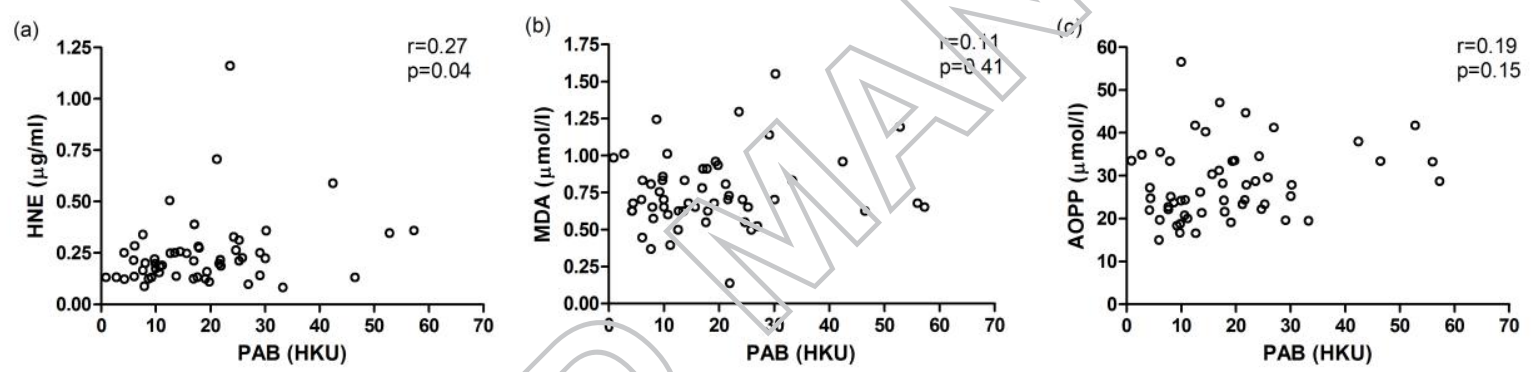


\section{Figure 2:}

(a)

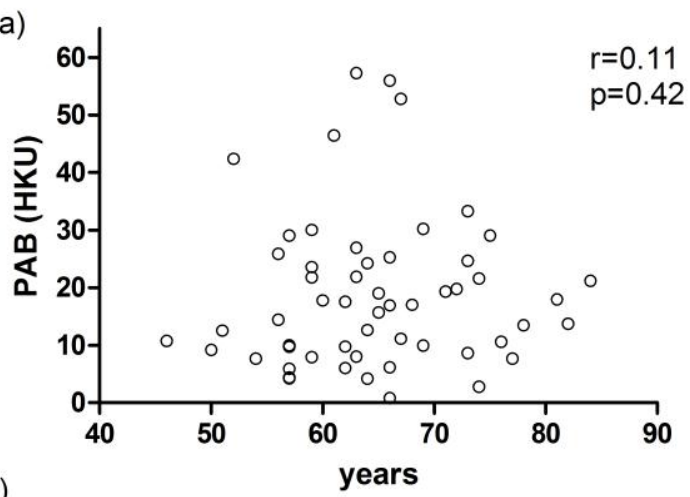

(c)

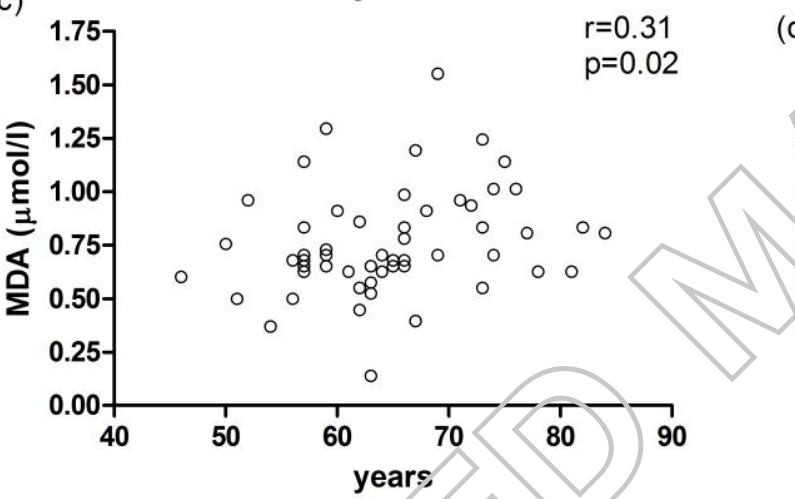

(b)
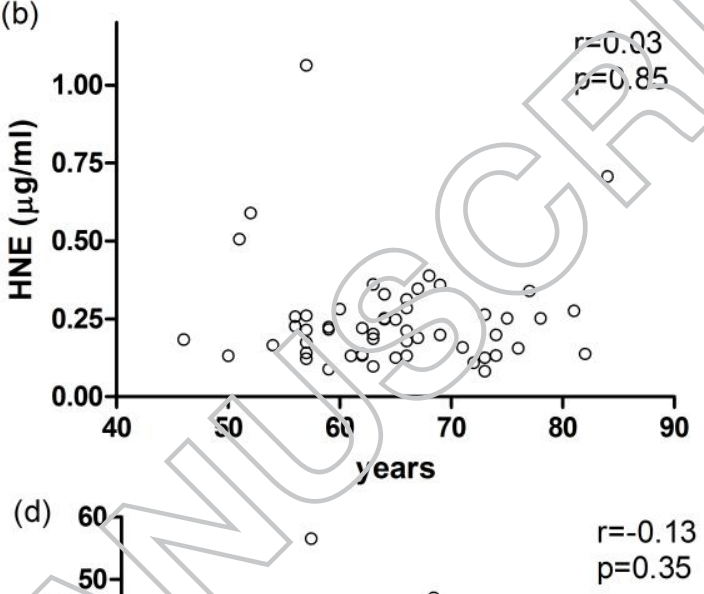

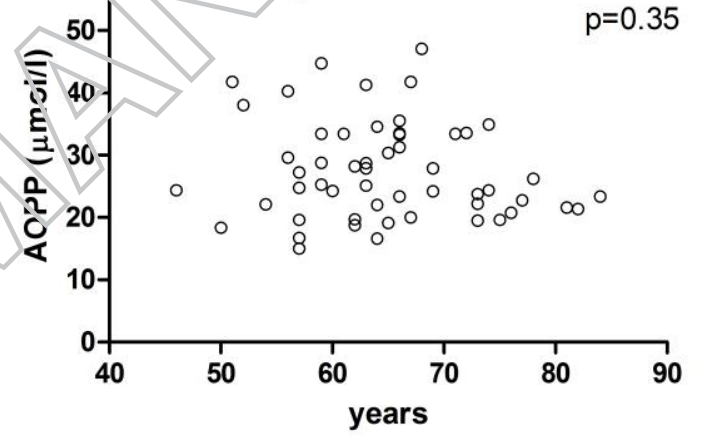


Figure 3:

(a)

(c)
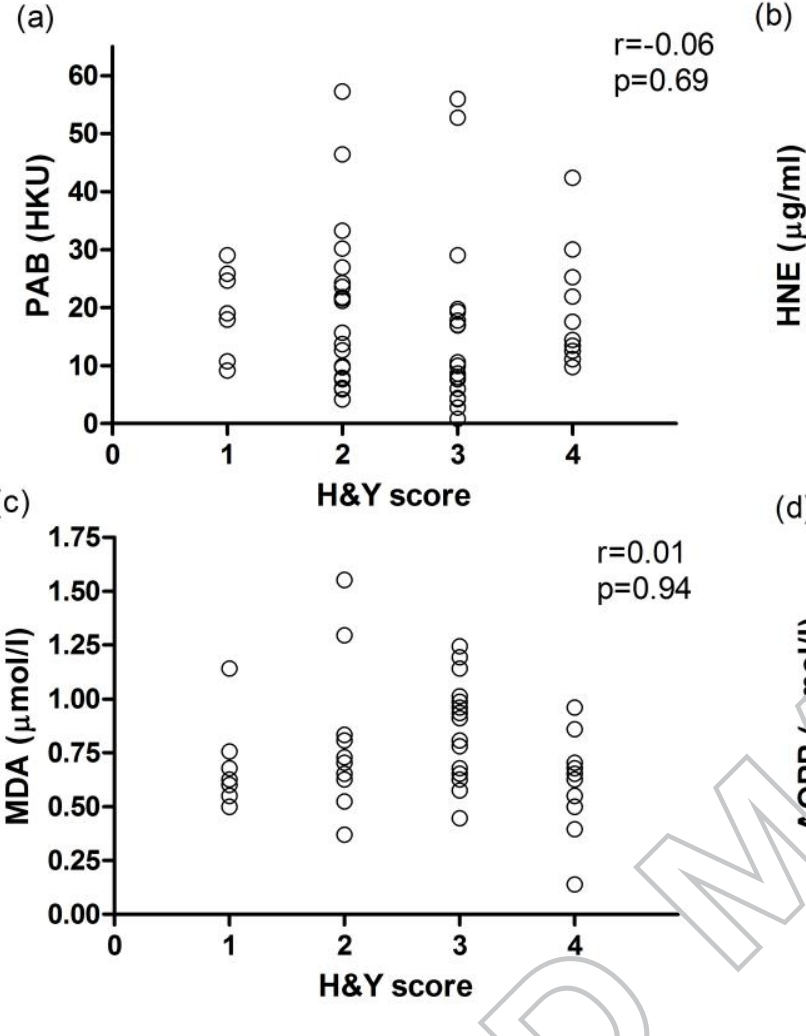

(b)

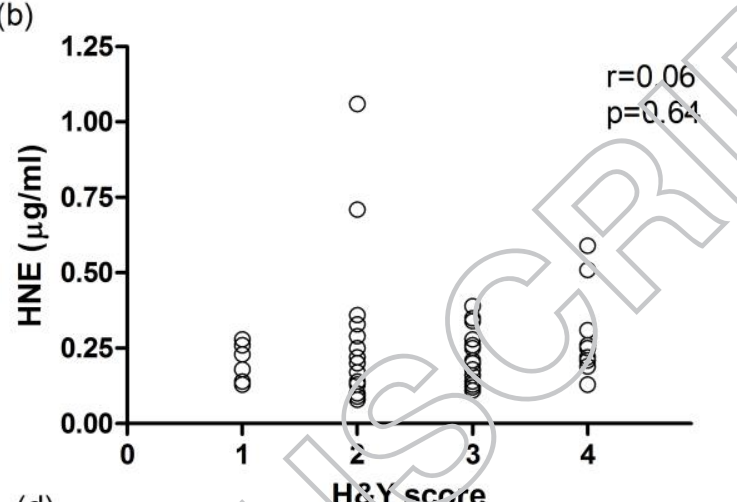

(d)

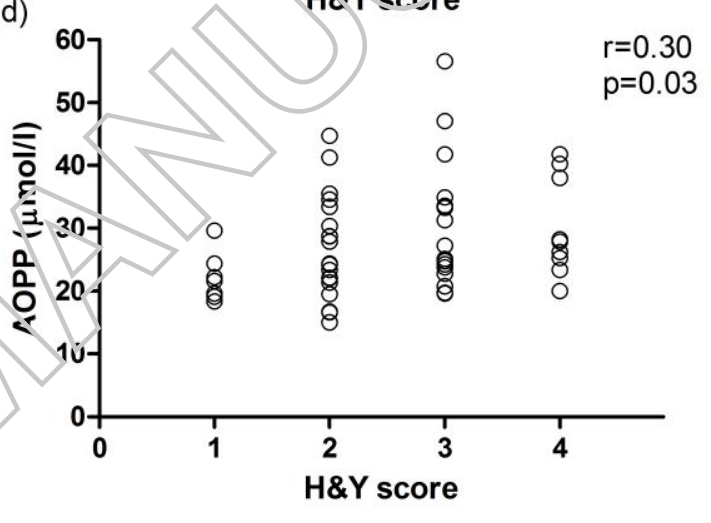




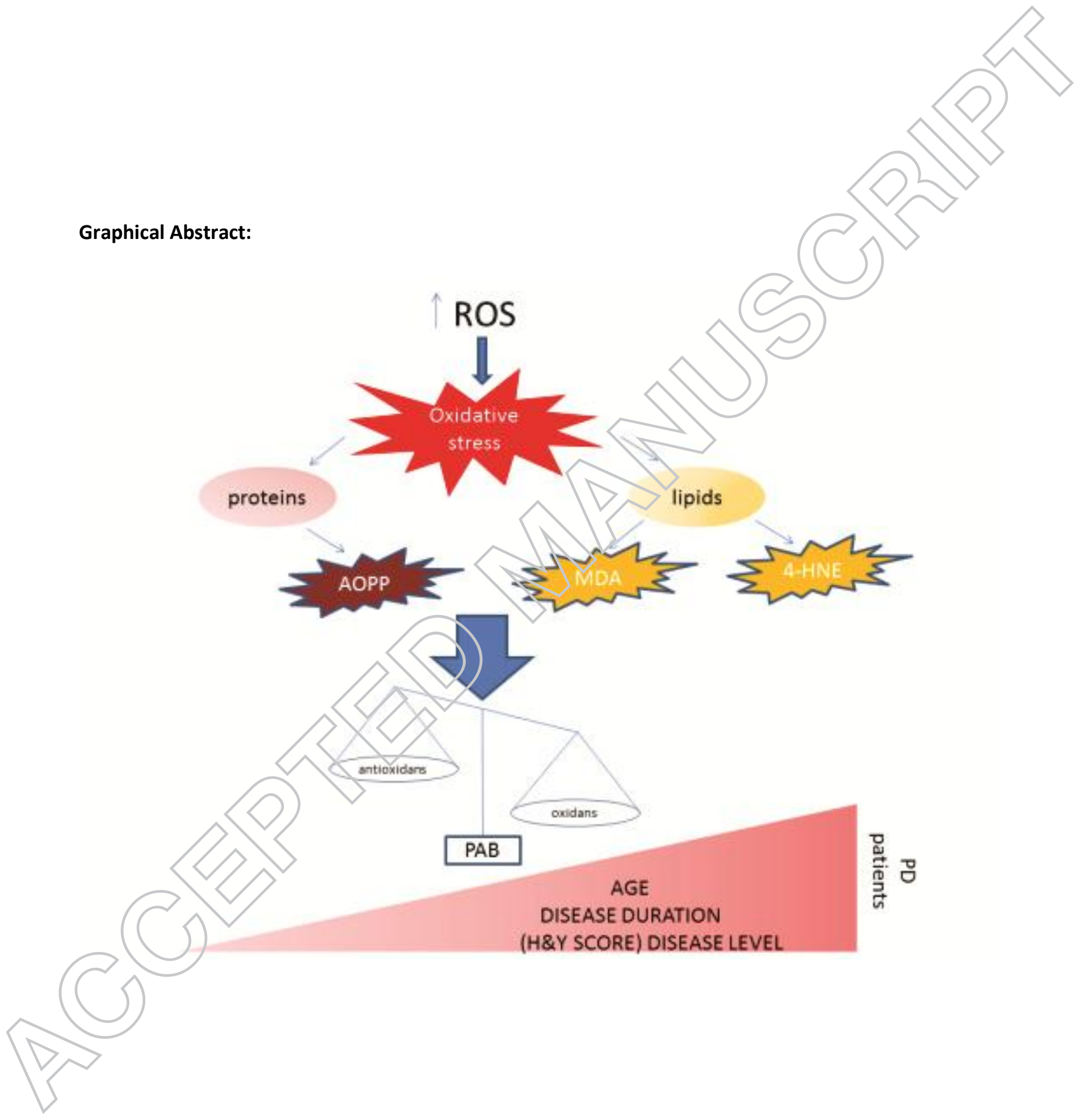


Table 1. Demographic and clinical data of patients with PD

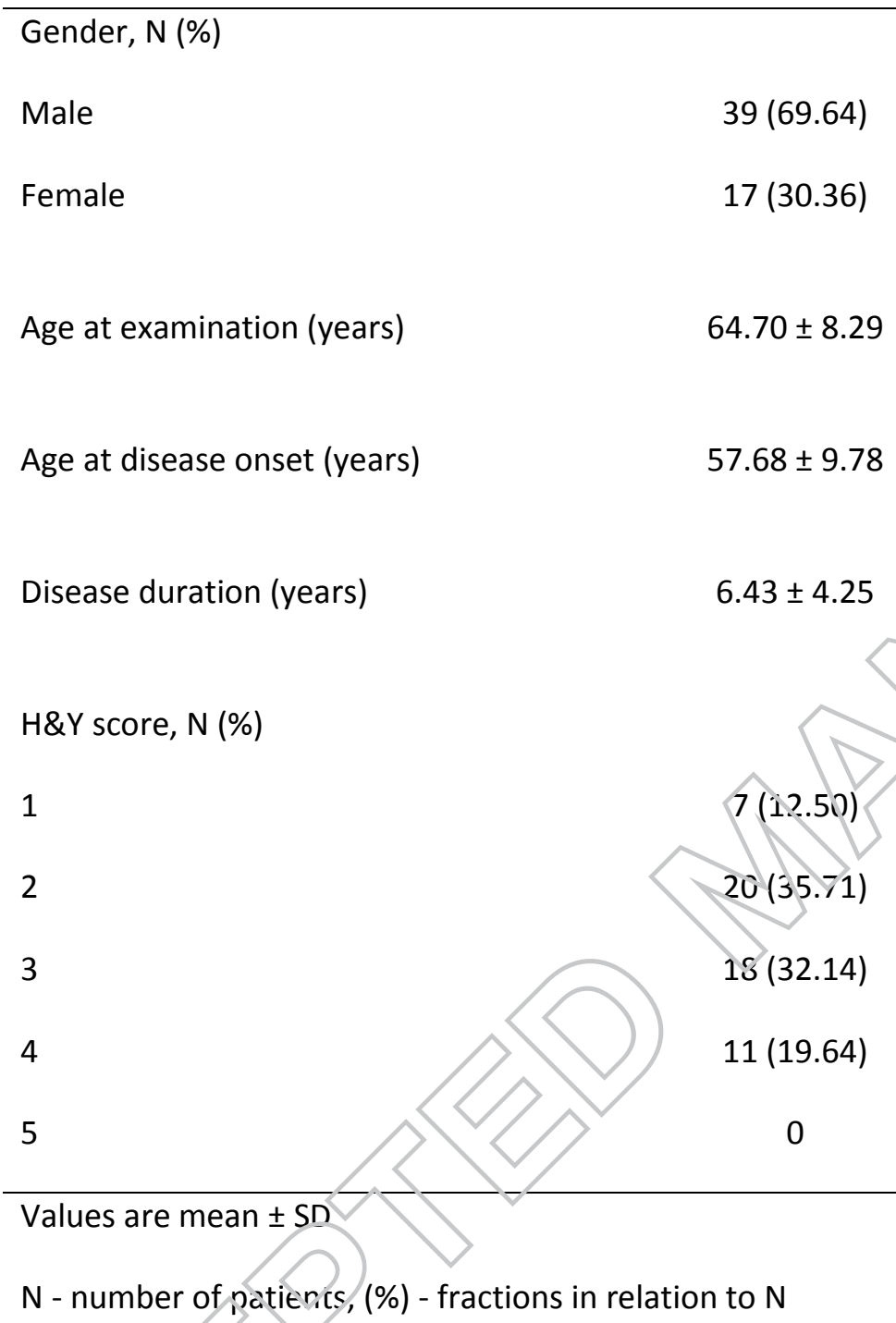


Table 2. 4-HNE, MDA, PAB and AOPP levels in plasma of patients with PD, in relation to clinicopathological characteristics

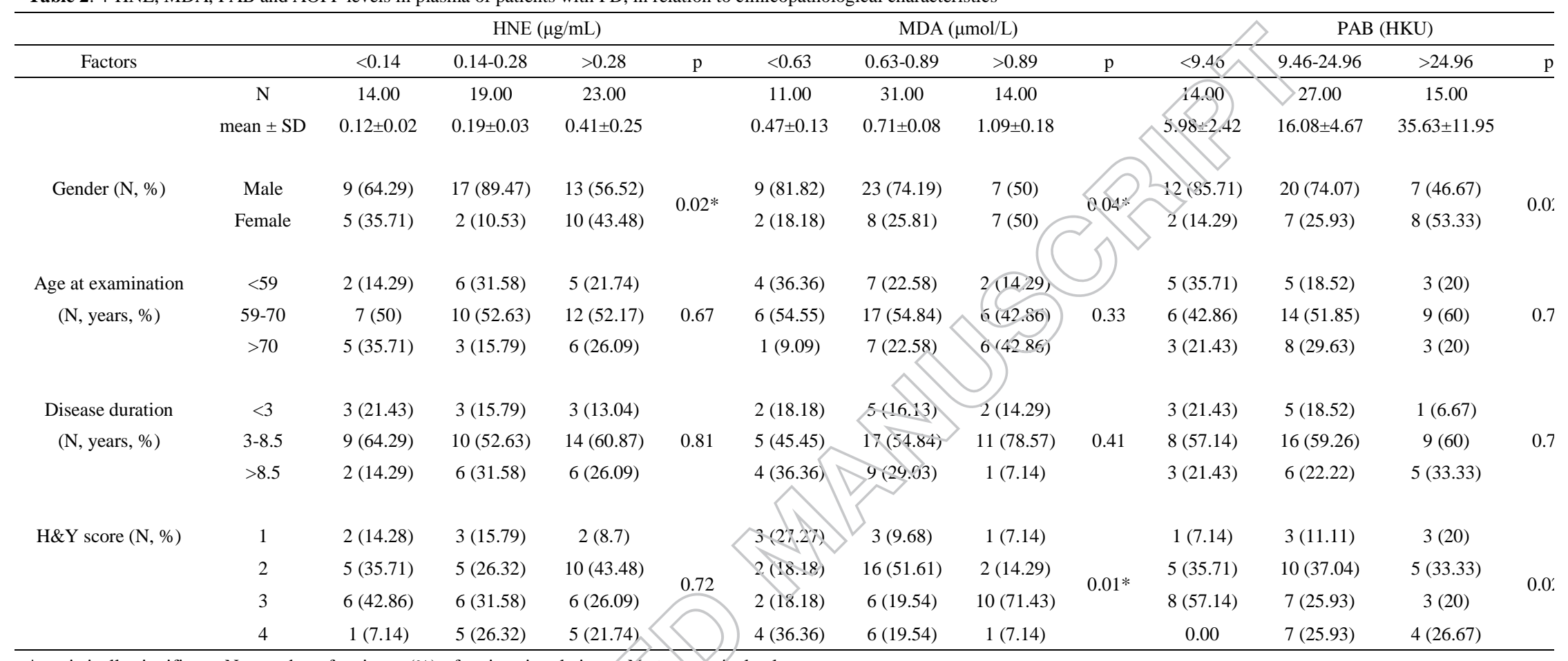

* statistically significant, $\mathrm{N}$ - number of patients, $(\%)$ - fractions in relation $\% 0 \mathrm{~N}, \mathrm{p}$ - statistical values 
Table 3. GLM univariate analysis of the associations between clinical and biochemical parameters.

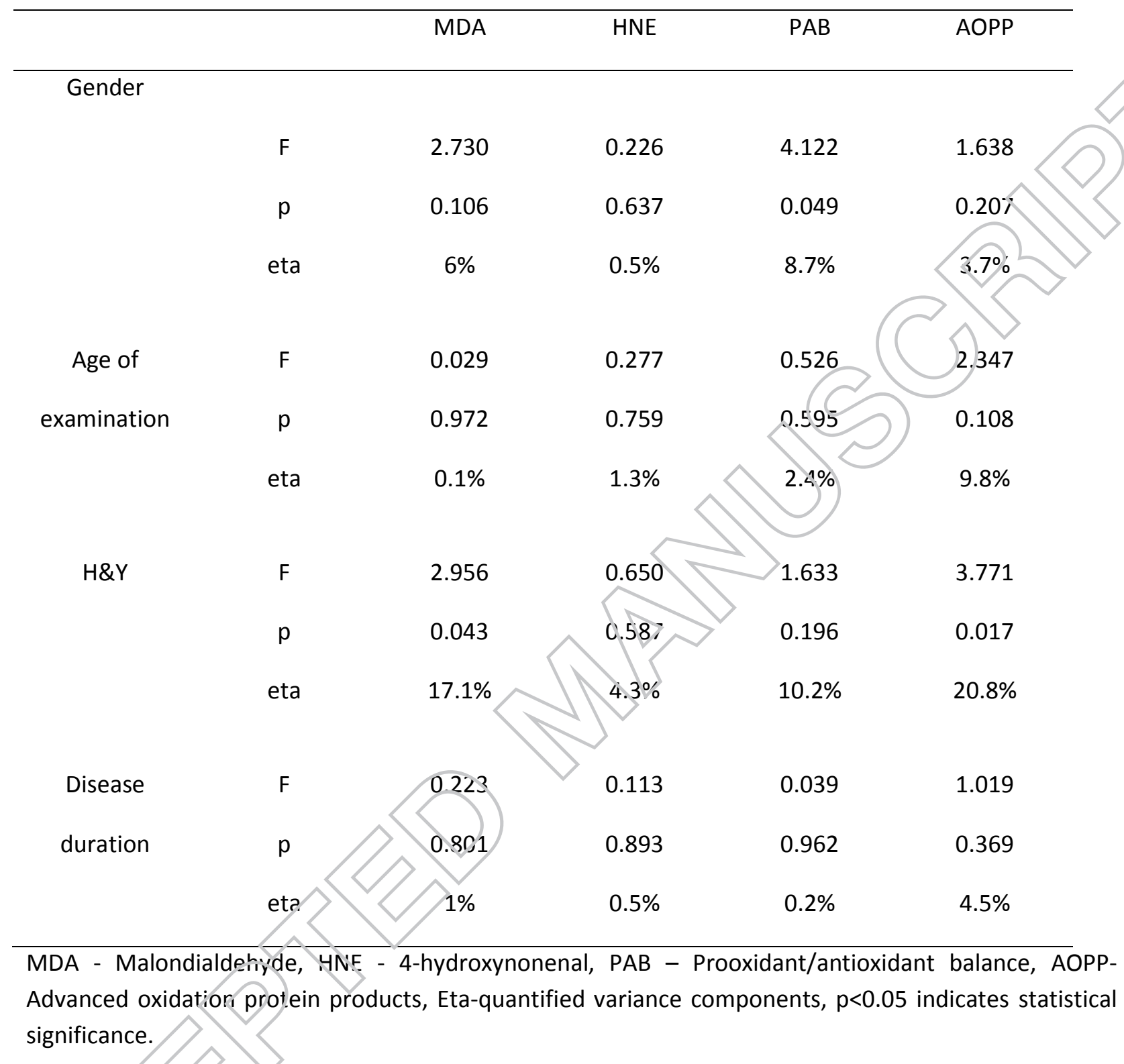

